\title{
Clinical applications for intraoperative optical coherence tomography: a systematic review
}

Citation for published version (APA):

Muijzer, M. B., Schellekens, P. A. W. J., Beckers, H. J. M., De Boer, J. H., Imhof, S. M., \& Wisse, R. P. L. (2022). Clinical applications for intraoperative optical coherence tomography: a systematic review. Eye, 36(2), 379-391. https://doi.org/10.1038/s41433-021-01686-9

Document status and date:

Published: 01/02/2022

DOI:

10.1038/s41433-021-01686-9

Document Version:

Publisher's PDF, also known as Version of record

Document license:

Taverne

Please check the document version of this publication:

- A submitted manuscript is the version of the article upon submission and before peer-review. There can be important differences between the submitted version and the official published version of record.

People interested in the research are advised to contact the author for the final version of the publication, or visit the DOI to the publisher's website.

- The final author version and the galley proof are versions of the publication after peer review.

- The final published version features the final layout of the paper including the volume, issue and page numbers.

Link to publication

\footnotetext{
General rights rights.

- You may freely distribute the URL identifying the publication in the public portal. please follow below link for the End User Agreement:

www.umlib.nl/taverne-license

Take down policy

If you believe that this document breaches copyright please contact us at:

repository@maastrichtuniversity.nl

providing details and we will investigate your claim.
}

Copyright and moral rights for the publications made accessible in the public portal are retained by the authors and/or other copyright owners and it is a condition of accessing publications that users recognise and abide by the legal requirements associated with these

- Users may download and print one copy of any publication from the public portal for the purpose of private study or research.

- You may not further distribute the material or use it for any profit-making activity or commercial gain

If the publication is distributed under the terms of Article $25 \mathrm{fa}$ of the Dutch Copyright Act, indicated by the "Taverne" license above, 


\title{
Clinical applications for intraoperative optical coherence tomography: a systematic review
}

\author{
Marc B. Muijzer $\mathbb{D}^{1}{ }^{凶}$, Peter A.W.J. Schellekens ${ }^{1}$, Henny J. M. Beckers ${ }^{2}$, Joke H. de Boer ${ }^{1}$, Saskia M. Imhof ${ }^{1}$ and Robert P. L. Wisse $\mathbb{D}^{1}$
}

(c) The Author(s), under exclusive licence to The Royal College of Ophthalmologists 2021

In this systematic review, we provide an overview of the current state of intraoperative optical coherence tomography (iOCT). As iOCT technology is increasingly utilized, its current clinical applications and potential uses warrant attention. Here, we categorize the findings of various studies by their respective fields, including the use of IOCT in vitreoretinal surgery, corneal surgery, glaucoma surgery, cataract surgery, and pediatric ophthalmology. The trend observed in recent decades towards performing minimally invasive ophthalmic surgery has caused practitioners to recognize the limitations of using a conventional surgical microscope for intraoperative visualization. Thus, the superior visualization provided by iOCT can improve the safety of these surgical techniques and promote the development of new minimally invasive ophthalmic surgeries. Landmark prospective studies found that iOCT can significantly affect surgical decision making and can cause a subsequent change in surgical strategy, and the use of iOCT has potential to improve surgical outcome. Despite these advantages, however, iOCT is still a relatively new technique, and beginning users of iOCT can encounter limitations that can preclude their reaching the full potential of iOCT and in this respect several improvements are needed.

Eye; https://doi.org/10.1038/s41433-021-01686-9

\section{INTRODUCTION}

\section{A brief history of intraoperative optical coherence tomography}

Optical coherence tomography (OCT) is a non-invasive in vivo imaging technique used to obtain micron-resolution $2 \mathrm{D}$ and $3 \mathrm{D}$ images of ocular tissues. The first OCT images were published back in 1993 [1], and in the following three decades OCT went from an object of research to an indispensable tool for studying, diagnosing, and treating ocular diseases [2]. Relatively recent the OCT was first introduced in the surgical theater for intraoperative imaging and it has promising potential for a new paradigm shift in ophthalmic surgery.

OCT is a non-contact tomographic imaging modality that uses infrared light interferometry. The single interferograms (i.e., Ascan) are laterally combined to create a cross-sectional plane called a B-scan (Fig. 1) [3]. The high spatial resolution of modern OCT devices enables the clinician to easily differentiate tissues and layers and thank to the clear optical structures in the eye the signal is not perturbed. Furthermore, the use of OCT in practice is safe for both the patient and the clinician, as OCT does not emit harmful radiation. The development of OCT technology made systems increasingly compact and mobile, expanding its application from table-top devices, to slit-lamp mounted, handheld devices and integration into microscopes or probes [4-7].

The first experiences with intraoperative OCT (iOCT), acquired with a handheld OCT device, were reported in 2005 [5]. The first IOCT systems were either a handheld OCT device mounted to the surgical microscope or table-top devices were integrated into a microscope through its eyepiece $[7,8]$. Similar integrated customdesigned OCT systems were also developed at Duke University and by Ehlers and colleagues at Cleveland Clinic [9-12]. This led to the development and commercialization of fully integrated systems into surgical microscopes with direct assessment capabilities, for example the inclusion of a heads-up display in the eyepieces [10, 12-14].

The technical possibilities of iOCT evidently underwent significant improvement. More recently, also the clinical possibilities for using OCT during surgical procedures are taking shape, and there is a growing body of research in all ophthalmic surgical domains that can be used to evaluate the utility and added value of iOCT in ophthalmic surgery. Here, we provide a comprehensive systematic review of the current knowledge regarding iOCT and its applications.

\section{METHODS}

A structured literature search of titles and/or abstracts in Pubmed and Embase was performed on September 29th 2020. The literature search was performed according to the preferred reporting items for systematic reviews and meta-analyses (PRISMA) guidelines [15]. The search terms included: "optical coherence tomography ocular surgery", "intraoperative optical coherence tomography", "microscope-integrated optical coherence tomography" "intraoperative optical coherence tomography eye", and all relevant synonyms and abbreviations. No date restrictions were set. The titles and abstracts of all retrieved

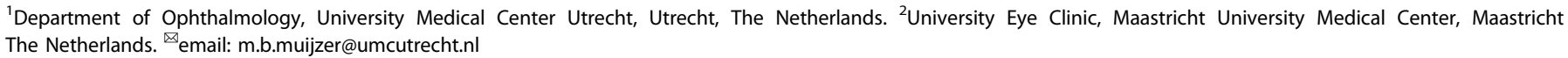

Received: 22 January 2021 Revised: 17 June 2021 Accepted: 1 July 2021

Published online: 16 July 2021 


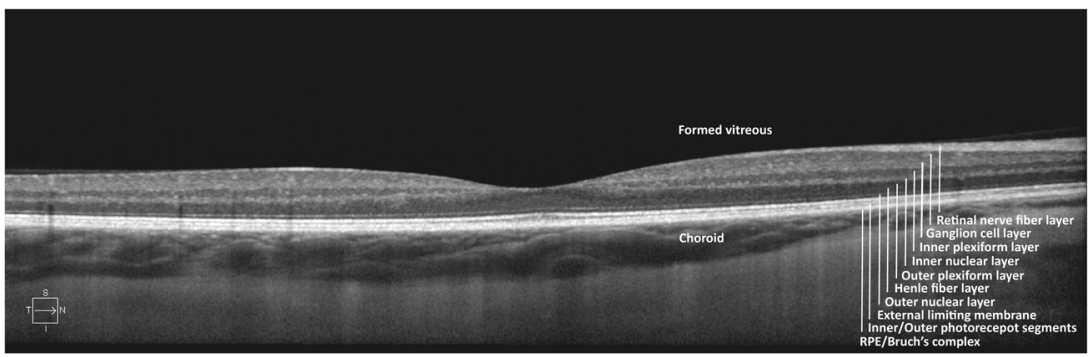

Fig. 1 An OCT cross-sectional image (B-scan) of a healthy human retina. The different retinal layers can be distinguished using the reflective properties of the layers and tissues. These reflective properties result in hyperfluorescent and hypofluorescent tissues, and the image is typically converted to a grayscale (shown) or pseudocolor image (not shown) in order to highlight the retinal layers.

articles were screened using pre-specified criteria for inclusion by two reviewers (M.M. and N.W.). The references of identified articles were manually checked to find potential relevant studies. Studies were included for full-text review and qualitative analysis if they reported on clinical applications and outcomes of iOCT. Studies were excluded if they reported non-original research, reported on cadaver/non-human/mock eyes, or were either a non-peerreviewed article, review, comment, case report, case series with less than 5 eyes, and/or were not published in English.

The included studies were independently evaluated by the same two reviewers (M.M. and N.W.) to assess; the strength of evidence according to the Oxford Centre for Evidence-Based Medicine (OCEM) 2011 guidelines, the quality of evidence according to the Grading of Recommendations Assessment, Development and Evaluation (GRADE) guidelines, and were critically appraised using the Joanna Briggs institute critical appraisal tool for case series, as the majority of identified studies were classified as case series [16-19]. Disagreement between the reviewers was resolved by discussion and a third reviewer (R.W.) was consulted if necessary. The included studies were qualitatively analyzed and grouped in the following domains; clinical decision making, vitreoretinal surgery, corneal and refractive surgery, cataract surgery, glaucoma surgery, pediatric ophthalmic surgery. The study design, number of subjects, level of evidence, critical appraisal, intervention and main findings related to IOCT were summarized in a table for each of the domains (see Supplementary Data). The studies reporting on retinal membrane peeling and macular hole surgery, and refractive surgery were summarized in separate table.

\section{RESULTS}

A total of 1283 studies were identified after the initial literature search. A detailed overview of the selection process and reasons for exclusion after full-text screening is shown in Fig. 2. After title and abstract screening 231 full-text articles were assessed for eligibility. For 16 articles the full-text was not available and attempts were made to retrieve these articles using other databases without success. Finally, after full-text review 102 articles were included for qualitative analysis. A detailed overview of the included studies, design, level of evidence, critical appraisal, and main findings can be found in the Supplementary Data. In the following subsections the outcomes of included studies are presented within their respective domain.

\section{FEASIBILITY OF INTRAOPERATIVE OCT AND IMPACT ON CLINICAL DECISION MAKING}

The technological advancements of OCT made the systems increasingly mobile and compact, however, implementation of iOCT faced operational hurdles which prevented widespread adoption. First, the conditions for image acquisition are challenging, such as a sterile environment and supine patient.

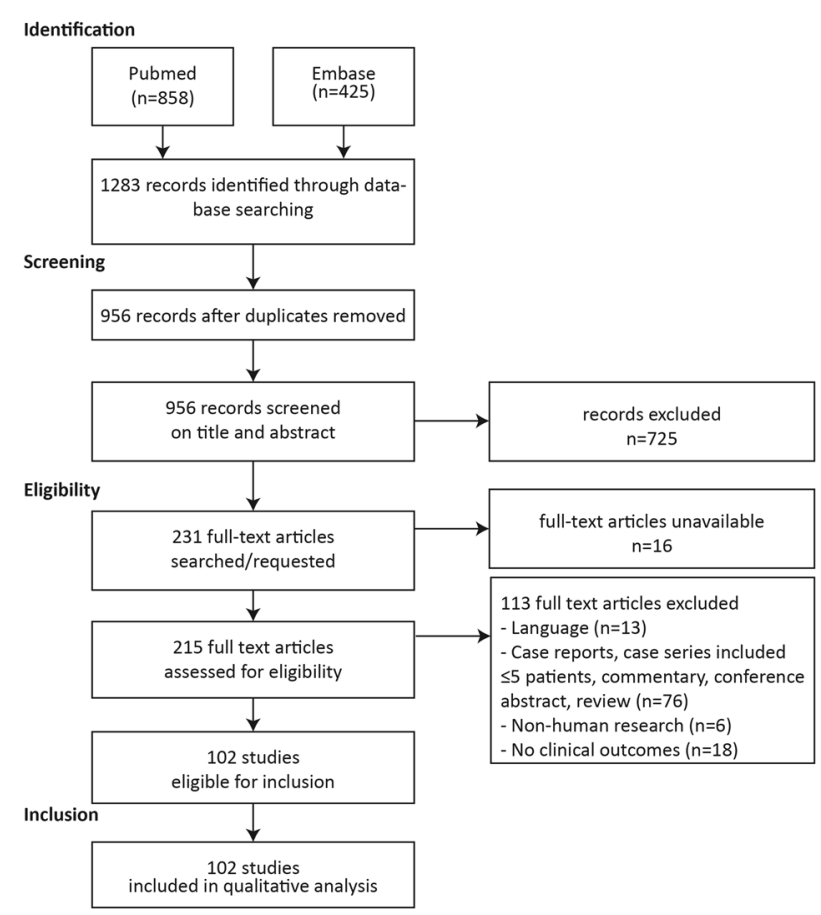

Fig. 2 The PRISMA flowchart of the literature search. Flow diagram of study identification, study exclusion, full-text review, and study inclusion.

Second, image acquisition delays surgical workflow. Third, the OCT device is a significant investment with limited understanding of the benefits [20]. In this section we assess and the impact of iOCT on clinical decision making and review the different iOCT devices in use.

\section{Impact of intraoperative OCT on clinical decision making}

The introduction of $\mathrm{IOCT}$ in the surgical theater has offered surgeons a previously unreachable source of information (Fig. 3). A majority of early research focused on how this information was used by surgeons to aid clinical decision making (see Supplementary Table 1). The landmark prospective intraoperative and perioperative ophthalmic imaging with optical coherence tomography (PIONEER) and Determination of Feasibility of Intraoperative Spectral Domain Microscope Combined/ Integrated OCT Visualization During En Face Retinal and Ophthalmic Surgery (DISCOVER) studies by Ehlers et al. thoroughly investigated the impact of iOCT on clinical decision making $[20,21]$. In the PIONEER study the iOCT image altered surgical decision making in $68 \%$ of posterior lamellar keratoplasty and $46 \%$ of retinal membrane peeling procedures [20]. Similarly, in the DISCOVER study the OCT 


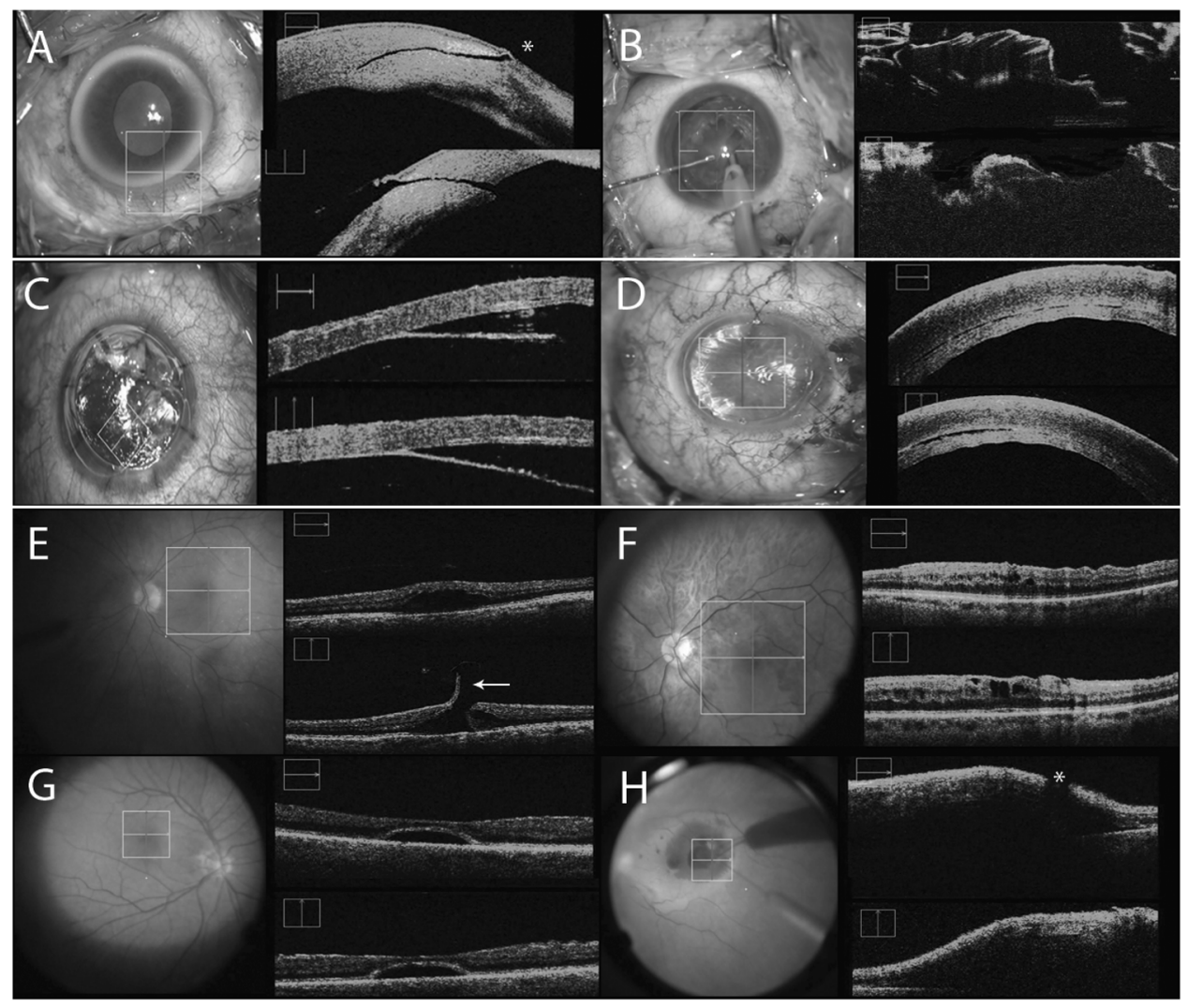

Fig. 3 Examples of iOCT use. In each panel, the picture on the left shows an en face microscope image, and the corresponding live OCT images are shown on the right in two perpendicular planes (indicated by purple and turquoise crosshairs). An example of a self-sealing incision (indicated by the asterisk in A) and assessment of the groove depth during phacoemulsification (B). Separation of the stroma and Descemet's layer during deep anterior lamellar keratoplasty $(\mathbf{C})$, and assessment of the interface fluid in Descemet stripping automated endothelial keratoplasty (D). The thin layer of hyporeflectivity between the graft and stroma indicates the presence of fluid. Intraoperative macular hole formation (E) with a membrane strand still attached to the retina (indicated by the arrow) and intraretinal cystic changes (F). The green indocyanine staining shows an incomplete staining of the inner limiting membrane, indicating the presence of an epiretinal membrane. Which can be confirmed in the OCT image. Retained subretinal fluid (G) and tPA injected for submacular hemorrhage (H); the asterisk in $\mathbf{H}$ indicates the needle injection site, and the absolute shadowing in the microscope image in $\mathbf{H}$ indicates the presence of highdensity material.

image provided valuable feedback in $\sim 60 \%$ of surgeries, thereby altering surgical decision making in $46 \%$ of anterior segment surgeries and $29 \%$ of posterior segment surgeries [21]. The benefit of OCT-probes has not been demonstrated in large cohorts, but Mura et al. reported that using a OCT probe it was possible to image the retinal periphery, vitreous base and ciliary body, which would be challenging or even impossible using a conventional surgical microscope or other iOCT systems [4].

Other studies reporting on the impact of IOCT on clinical decision making report similar results as the PIONEER and DISCOVER study $[8,14,22-25]$. The results of these studies suggest that the IOCT fills the gaps in surgical information and these insights may improve quality of care and surgical efficiency. Examples of surgical information provided by the iOCT included assessment of the completeness of retinal membrane peeling and adherence of posterior lamellar keratoplasty grafts. A detailed review of the impact and benefit of iOCT is provided in the following subsection for each surgical domain. Notwithstanding, the bias in the design of these studies deserves attention. In all studies the IOCT system was available to use at the surgeons discretion and in none of the studies the researchers randomized for iOCT use. The evidence of the benefits of iOCT therefor remain indirect. In addition, the availability of iOCT may also lead to potential problems, such as data overload and fixation on irregularities of which the clinical relevance is unclear.

\section{Intraoperative OCT devices}

Three types of iOCT devices are currently used in practice (i.e., (mounted) handheld, microscope-integrated, and instrument/ probe integrated) and these device types have their respective benefits and limitations. Handheld devices can be used in concordance to a surgical microscope, but also as a stand-alone device [20]. This flexibility is also their most notable advantage compared to dedicated iOCT platforms. However, the handling of a handheld device can be challenging because the system, if not mounted, is unstable which makes image acquisition difficult and has a steep learning curve $[5,20,26]$. To this end handheld devices are mounted (i.e., attached to the surgical microscope) and can be moved in place for image acquisition. The mounted systems use the stability and precise maneuverability in the $x, y$, and $z$ plane offered by the surgical microscope, thereby significantly improving the speed, accuracy and reproducibility of iOCT imaging [20]. In the PIONEER study Ehlers et al. successfully obtained intraoperative images using a mounted handheld device in $98 \%$ of the eyes with a minimal impact on surgical workflow [20]. The median time to set up the iOCT was $1.7 \mathrm{~min}$ and the median time the surgery was paused measured $4.9 \mathrm{~min}$ per scan session [20].

Notwithstanding, pausing the surgery for image acquisition remains a major disadvantage of handheld systems. Moreover, during the PIONEER study a technician was present to support imaging and image acquisition may be more complicated without support [20]. 
A microscope-integrated iOCT has several advantages compared to handheld devices. First, the integrated system can be used can be used without pausing the surgery and during surgical maneuvers, thereby disrupting the surgical workflow less and lowering the threshold for its use. Second, integrating into the surgical microscope facilitates independent use by the surgeon without support of a technician. Third, the design creates more possibilities to integrate tools and algorithms to enhance surgery, such as decision aids and surgical guidance tools [12].

Lastly, OCT technology has advanced to the point it can be integrated into probes and instrument for intraocular use. In contrast to handheld and integrated systems OCT probes and OCT-integrated instruments were developed to provide maximal flexibility during vitreoretinal surgery [4]. Using an OCT probe or instrument, the ciliary body and peripheral retina can be imaged easily, and image acquisition is not affected by the presence of cloudy media [4]. Despite these advantages, however, these probes and instruments have several disadvantages as well, including a limited field of view, a vulnerable design, costly nonreusable probe tips, relatively high risk of contamination, difficult image acquisition, and a steep learning curve for the surgeon $[4,27,28]$.

\section{VITREORETINAL SURGERY}

The use of OCT revolutionized the diagnosis and treatment of vitreoretinal diseases, and has become an indispensable tool in this field [2]. As result, iOCT was initially targeted primarily to vitreoretinal surgeons. Despite early research interest, iOCT has not yet enjoyed the same popularity as their table-top counterparts. Nevertheless, the body of research regarding iOCT during vitreoretinal surgery is extensive. Several studies have shown that the findings on the iOCT image can aid and alter surgical decision making in about $30-40 \%$ of vitreoretinal surgeries [20, 21]. The iOCT images provide valuable insights in tissue dynamics and alterations following surgical interventions. As a diagnostic device the IOCT can be used to evaluate the retina for underlying conditions [29]. For example, in cases with a vitreous hemorrhage, pathology can be excluded or-if possible-treated [30, 31]. Moreover, the direct imagery of iOCT allows for early detection of adverse events and management of these events [32-34].

The use of IOCT has been reported for a variety of routine vitreoretinal procedures such as macular surgery and retinal detachment surgery (see "Retinal membrane peeling and macular hole surgery" and "retinal detachment surgery"), but also for challenging surgeries which entail a considerable risk of misplacement, incorrect removal of tissue, scar tissue formation, and/or poor surgical outcomes. Examples of challenging interventions were the in-depth visualization and assistance of IOCT is reported are; the placement of retinal implants and medical devices in the vitreous cavity [35, 36], retinal biopsies [37], cystotomy for deroofing macular cysts [38], and subretinal and submacular injections [39]. In particular, the use of subretinal and submacular injections is expected to increase and are crucial for novel gene therapies. The iOCT image allows for the genetic material to be delivered with improved accuracy [39]. The complete overview of included studies and outcomes can be found in Supplementary Table 2 (macular surgery) and 3 (vitreoretinal surgery).

\section{Retinal membrane peeling and macular hole surgery}

The peeling of membranes of the retina (e.g., internal limiting membrane (ILM), epiretinal membrane (ERM), and pucker peelings) is a frequent performed procedures and among procedures in which the iOCT is most utilized $[20,21]$. The iOCT can be used to determine the starting point for the peel, to check for retina/ macular hole formation after peeling, and/or to confirm that the peel is completed (see Supplementary Table 2) [20, 21, 33, 40-44].
Several studies revealed a considerable disagreement between the surgeon's observation and the OCT image in regard to peel completeness [20, 21, 41, 43, 44]. For example, in the DISCOVER study the IOCT showed residual membranes when the surgeon believed that the membrane was fully peeled in $20 \%$ of the cases. Conversely, in $40 \%$ of cases in which the surgeon suspected a residual membrane, iOCT revealed that the peel was complete, preventing the need for unnecessary surgical action [21]. Membrane peeling without the use of chromovitrectomy dyes has also been performed, albeit with limited success [41, 43]. Leisser et al. reported successful peeling of the ERM without the use of dyes [43]. Although no significant differences in outcomes were found between the use of dyes and dye-free peeling. Moreover, chromovitrectomy dyes were still necessary for staining the ILM and posterior hyaloid. Another factor that may limit the success of performing dye-free iOCT-assisted membrane peeling is the shadow that metallic instruments cast over the peeling area, as well as suboptimal visualization of thin membranes [21,41]. The use of intravitreal dyes to enhance OCT contrast (i.e., dyeing the membranes to improving visualization on the shown potential for iOCT-assisted membrane peeling and may improve surgeon feedback on the completeness of the peel. Indocyanine green, which is a widely used dye, enhances the reflectivity of the ILM and ERM (contrast ratio increased from 0.907 to $1.42, p<0.001$ ) [45]. Similarly, tissue reflectivity improved using triamcinolone and prednisolone acetate, though all contrast agents resulted in shadowing of the underlying tissue [45].

Furthermore, IOCT has also been used to increase our understanding of tissue-instrument interactions and gain insight in retinal alterations after membrane peeling. The retina is a delicate tissue that can be damaged easily by surgical instruments. This has led to the introduction and preferences for using minimally traumatic instruments in recent years. On the other hand, no association has been found between increased retinal damage and subsequent alterations when using a specific type of instrument (e.g., pick, loop or duster) during membrane peeling [11,46-48]. During and immediately after peeling the ILM or ERM significant iatrogenic retinal alterations could be detected on the IOCT scans (see Supplementary Table 2), though the detected alterations resolved rapidly after releasing traction or after surgery $[44,46,47,49-56]$. The impact of these transient alterations is not yet fully understood, but studies have found no association with long-term worsening of functional or anatomical outcomes $[47,49,52-54,57]$.

The utility of IOCT during surgical treatment of macular holes has also received extensive attention and the shows promising results (see Supplementary Table 2). During macular hole repair surgery the release of traction, efficacy of the tamponade, and closure of the hole can be directly assessed on the IOCT image $[25,40,58]$. In addition during inverted flap procedures the positioning of the flap in the macular hole can be observed, even after fluid-air exchange [25, 33, 59]. Assessing efficacy of tamponade and hole closure may be useful to tailor face-down positioning after surgery [60]. Furthermore, using the iOCT Kumar and Yadav were able to identify a novel intraoperative sign predictive of macular hole closure. Kumar and Yadav named this sign the 'hole-door-sign': residual vertical tissue pillars at the macular hole edge after ILM peeling [61]. Eyes with the hole-doorsign had a $100 \%$ rate of closure without an neurosensory defect compared to $60 \%$ of the eyes without the hole-door-sign [61]. The studies of Inoue et al. and Tao et al. confirmed the predictive value of the hole-door-sign for macula hole closure, however, the authors reported contradicting results regarding the postoperative visual acuity in eyes with the hole-door-sign [62, 63].

The use of iOCT also provided valuable insights in macular hole dynamics. After ILM peeling the macular hole height and central hole diameter were reported to remain stable, whereas hole volume, base diameter, base area, top/apex diameter, and 
top/apex area increased compared to before ILM peeling $[46,51,64]$. Based on these insights in macular hole dynamics Ehlers et al. investigated the predictive value of retinal tissue dynamics for early macular hole closure. Their predictive model had an area under the curve of 0.974 and the most robust predictors for early macular hole closure were intraoperative change in macular hole volume, intraoperative change in minimal width, and pre-incision minimal width [65]. Both the hole-doorsign as well as the predictive model of Ehlers et al. may be a first step towards customized surgery $[61,65]$. In this regard, the use of volumetric iOCT may facilitate implementation for these and similar tools analyzing tissue dynamics [66, 67].

Retinal detachment surgery. During surgical repair of retinal detachment (RD), the iOCT images can provide valuable information and aid clinical decision making, particularly in complex cases, as was shown by Abraham et al. [23]. They reported that in $50 \%$ of complex RD cases the iOCT provided valuable feedback - which altered surgical management in $12 \%$ of cases - compared to $21 \%$ in non-complex cases $(p=0.01)$ [23]. In cases of RD with macular involvement, significant amounts of occult non-resolving submacular fluid have been observed after perfluoro-n-octane instillation, direct drainage, or a drainage retinotomy [68]. The presence sub-macular fluid could delay visual recovery, but does not appear to impact postoperative functional or anatomical outcomes, specifically the ellipsoid integrity $[69,70]$. The significant changes of the retinal tissue have been found resembling alterations observed after macular surgery, ranging from hyper-reflectance to disruption of the retinal layers [71]. However, the majority of detected alterations did not impact the clinical decision making in both RD and macular surgery, because it is not possible or unclear how to prevent or resolve these alterations.

\section{CORNEAL AND REFRACTIVE SURGERY}

The use of IOCT in corneal surgery is rapidly growing in popularity. Specifically, easy imaging of the cornea contributes to the low threshold for adopting the use of iOCT in corneal surgery. The corneal surgeon experiences only minimal loss of focus when using $\mathrm{IOCT}$, and the optical properties of the cornea minimize shadowing of the image. The principal application of IOCT is in selective keratoplasty, which is considered to be technically demanding, particularly in cases with a cloudy or edematous cornea. The PIONEER and DISCOVER study showed the advantages associated with access to iOCT technology during selective keratoplasty; specifically, the new information provided by iOCT led a critical change in surgical decision making in, respectively, $48 \%$ and $43 \%$ of lamellar corneal surgeries $[20,21]$. In this section the applications and benefits of $\mathrm{IOCT}$ in corneal and refractive surgery are reviewed. The detailed overview of the included studies and outcomes can be found in Supplementary Tables 4 and 5 .

\section{Anterior corneal surgery}

Deep lamellar anterior keratoplasty (DALK) is the selective transplantation of the corneal stroma, leaving the recipients Descemet membrane and endothelium in place. During DALK, the Descemet's membrane and anterior stroma must be completely separated by either manual or big bubble dissection. However, both methods for separating the layers are at risk of complications and separation of the layers is difficult to visualize using the enface microscope view. In particular, successful big bubble formation in particular is dependent on the depth of the dissection plane for cannula placement [72]. The iOCT enables the surgeon to directly assess the depth of the dissection plane and if necessary place additional cuts or reposition the cannula [73]. Additionally, after injecting air between the corneal layers the surgeon can confirm separation of the layers and Descemet's membrane integrity $[74,75]$. Initials reports using iOCT during DALK showed that a deeper trephination depth can be achieved and the cannula can be placed closer to the Descemet's membrane (successful big bubble: $90.4 \pm 27.7 \mu \mathrm{m}$, failed big bubble: $136.7 \pm 24.2 \mu \mathrm{m}, p<0.01$ ), leading to a high rate of successful big-bubbles ( $\geq 70 \%)[72,74]$. Moreover, the use of iOCT enables the surgeon to attempt manual dissection in the case of an emphysematous opaque cornea after a failed attempt using the big bubble method [74, 75]. Lastly, Guindolet et al. reported that femtosecond laser DALK with IOCT assistance resulted in a $100 \%$ success rate with respect to big bubble formation, with no perforations, in eighteen DALK procedures [76]. They attributed this success to the accuracy of femtosecond laser cuts combined with direct assessment of corneal thickness using iOCT.

Similarly to assessing the dissection plane in DALK surgery Zakaria et al. used iOCT to guide dissection depth during pannus removal in limbal stem cell transplantation [77]. During surgery OCT pachymetry maps were made to assess how much tissue was removed and prevent accidental corneal perforation. In all 8 cases the pannus was completely removed and no corneal perforations were recorded [77].

\section{Posterior lamellar corneal surgery}

Notable advantages of iOCT in corneal surgery are observed during posterior lamellar keratoplasty, such as Descemet stripping endothelial keratoplasty (DSEK) and Descemet membrane endothelial keratoplasty (DMEK), in which the posterior corneal layers are selectively replaced by a partial corneal graft [78]. A relative frequent and burdensome adverse event is postoperative detachment of the graft, which often necessitates additional surgical procedures. Although the underlying cause of graft detachment is considered multifactorial, though interface irregularities and/or the presence of fluid in the interface are believed to impede proper attachment of the graft [79]. In addition, interface fluid could lead to textural interface opacities and could negatively impact visual acuity [80]. The presence of interface fluid is not always evident in the en-face microscope view and the use of IOCT allows the surgeon to assess the interface in high detail, detect areas of non-adherence, or folds during surgery, which may require additional interventions (Fig. 4) [26, 81-84]. For example, in 46 of 84 DSAEK procedures of the DISCOVER study persistent interface fluid was visualized, in which the surgeon deemed the graft well-attachment [21]. In addition, the iOCT image provides insight in the efficacy of surgical maneuvers to reduce interface fluid and promote graft adherence, including: corneal swiping, venting incisions, and over-pressurizing the ocular globe $[82,85,86]$. All these maneuvers were reported to significantly reduce interface fluid in DSAEK. However, the independent use of prolonged overpressure of the globe may only marginally reduce interface fluid. Titiyal et al. reported that interface fluid persisted after $8 \mathrm{~min}$ of overpressure, whereas by combined overpressure and corneal swiping interface fluid disappeared within 3 min [87]. Recently, we performed a similar study in which the use of overpressure in DMEK surgery was evaluated compared to using a minimal pressurization time. Similarly, our results indicated that refraining from prolonged overpressure during DMEK increases surgical efficacy without increasing the risk of postoperative adverse events [79]. Refraining from prolonged overpressure does not appear to increase risk of graft detachment, reduces surgical time and may prevent damage to the optic nerve head, especially relevant for patient with preexisting glaucoma.

Furthermore, iOCT can be useful while determining orientation, unfolding, and positioning the graft during DMEK [84, 88, 89]. Proper orientation of the graft must be determined in order to ensure functional graft adhesion (Fig. 5). Currently used signs/ methods (e.g., the Moutsouris-sign, stamps or circular cuts) are not 


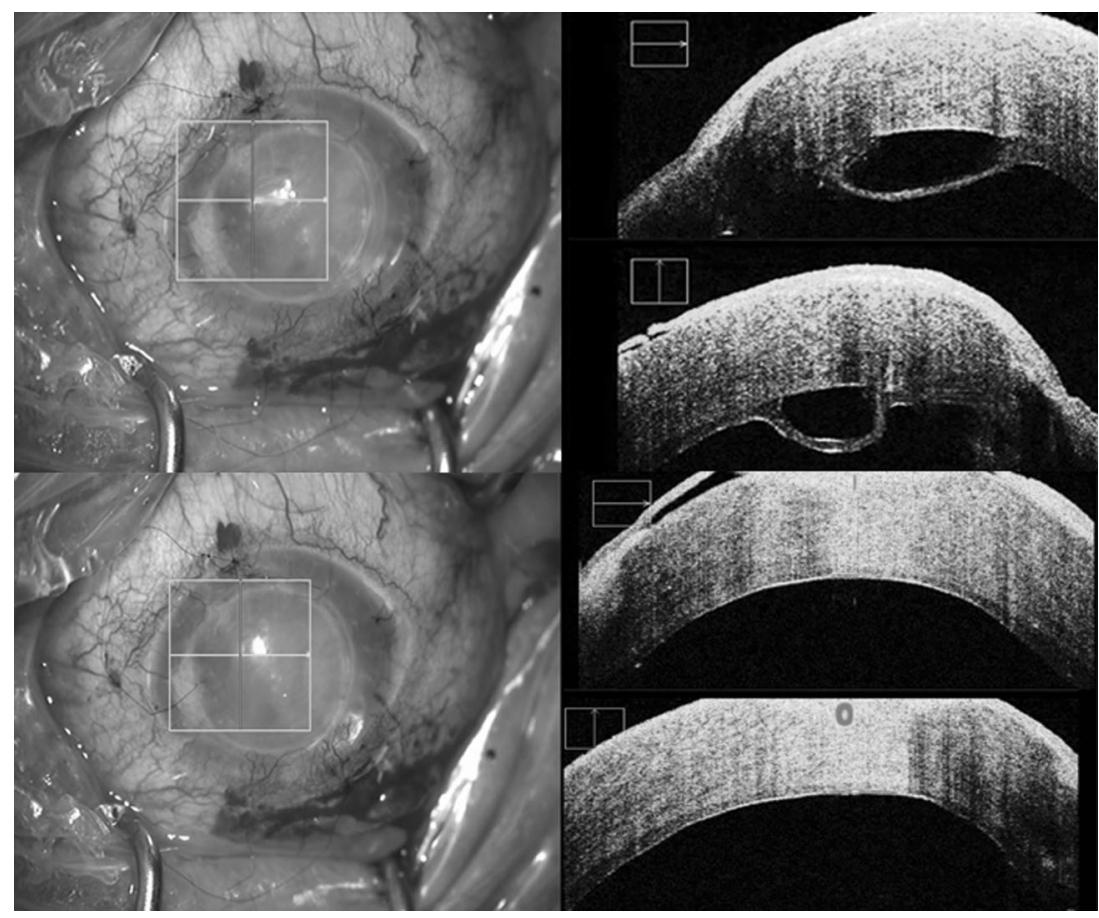

Fig. 4 iOCT reveals an interface fluid. In each panel, the picture on the left shows an en face microscope image, and the corresponding live OCT images are shown on the right in two perpendicular planes (indicated by purple and turquoise crosshairs). A An example of fluid/gas in the interface of a Descemet stripping automated endothelial keratoplasty (DSAEK). B The same cornea shown in A, with a completely attached DSAEK graft.

always self-evident and poor visualization hinder proper assessment $[88,89]$. Not to mention, both stamps and cuts damage the graft resulting in endothelial cell loss [79]. More recently, iOCT has been used to determine graft orientation as the iOCT signal is not perturbed by cloudy media [79, 90, 91]. The natural rolling behavior of DMEK grafts can be well appreciated on the iOCT image, thereby preventing the need to manipulate, cut, or mark the graft to determine the orientation, subsequently preventing endothelial cell loss. In addition, both Saad et al. and Patel et al. reported that $\mathrm{IOCT}$ resulted in a shorter duration for unscrolling and positioning the DMEK graft, thereby reducing graft manipulation and improving surgical efficiency $[88,91]$.

Incorporating iOCT-guidance in posterior lamellar keratoplasty can optimize both the surgical techniques and surgical outcome. Nevertheless, care should be taken with iOCT-guided surgery, as it can lead to more (rigorous) manipulation and a more aggressive surgical approach, potentially leading to graft damage [86]. For example, the high-resolution images provided by iOCT can reveal small folds, non-adherence, and interface irregularities for which the clinical significance is yet unclear.

\section{Corneal crosslinking and refractive surgery}

Corneal crosslinking $(C X L)$ is now the first-line treatment for progressive corneal ectasia, particularly keratoconus [92]. During CXL the penetration of riboflavin in the corneal stroma a key factor that determines treatment efficacy and IOCT has been successfully used to visualize the penetration depth of riboflavin by the noticeable hyper-reflectance of riboflavin [93]. Importantly, the depth of riboflavin penetration was lower in epithelium-on CXL $(149.39 \pm 15.63 \mu \mathrm{m})$ compared to epithelium-off procedures $(191.04 \pm 32.18 \mu \mathrm{m})$, suggesting that penetration depth could be used to determine treatment efficacy [93].

Several studies reported successful use of OCT to measure corneal thickness and/or corneal dissection depth during CXL and refractive surgery $[94,95]$. Compared to the current gold standard for measuring corneal thickness, ultrasound pachymetry, OCT pachymetry has several advantages. OCT pachymetry is a noncontact technique that uses the corneal apex reflection for alignment and a larger area of the cornea can be measured. This is relevant for CXL as it allows the thinnest part of the corneawhich is often paracentrally located - to be detected more easily and obtaining a thickness map of the entire cornea reduces the risk of inadvertently damaging the corneal endothelium due to UV radiation in CXL $[94,96]$. The agreement of measurements between OCT pachymetry and ultrasound pachymetry is high (intraclass correlation coefficient 0.80 ), and OCT measurements are highly repeatable. Therefore, iOCT pachymetry provides a more standardized measurement, with higher accuracy and negligible risks compared to ultrasound pachymetry [97]. Furthermore, Siebelmann et al. demonstrated the use of iOCT for determining the depth during corneal laser dissection and may be particularly beneficial for therapeutical corneal ablation, because preoperative OCT scans can become inaccurate during the docking process [98].

Titiyal et al. and Torbey et al. described the use of iOCT to assess the position and vaulting of implantable collamer lens $[99,100]$. In both studies a high significant correlation was found between intraoperative and postoperative vaulting (Titiyal et al. $r=0.954$; $p<0.001$; Torbey et al. $r=0.81, p<0.001)$ [99, 100]. This is clinically relevant, given that extreme vaulting is associated with a postoperative residual refractive error or postoperative complications such as cataract or iatrogenic acute glaucoma, which may necessitate removal of the lens [99].

\section{CATARACT SURGERY}

Although the use of iOCT during cataract surgery is still its infancy, it has high potential. Worldwide, cataract surgery is the most commonly performed form of ophthalmic surgery and is arguably one of the safest [101]. In this section we review the current applications and potential of $\mathrm{IOCT}$ during cataract surgery. A detailed overview of included studies and outcomes can be found 


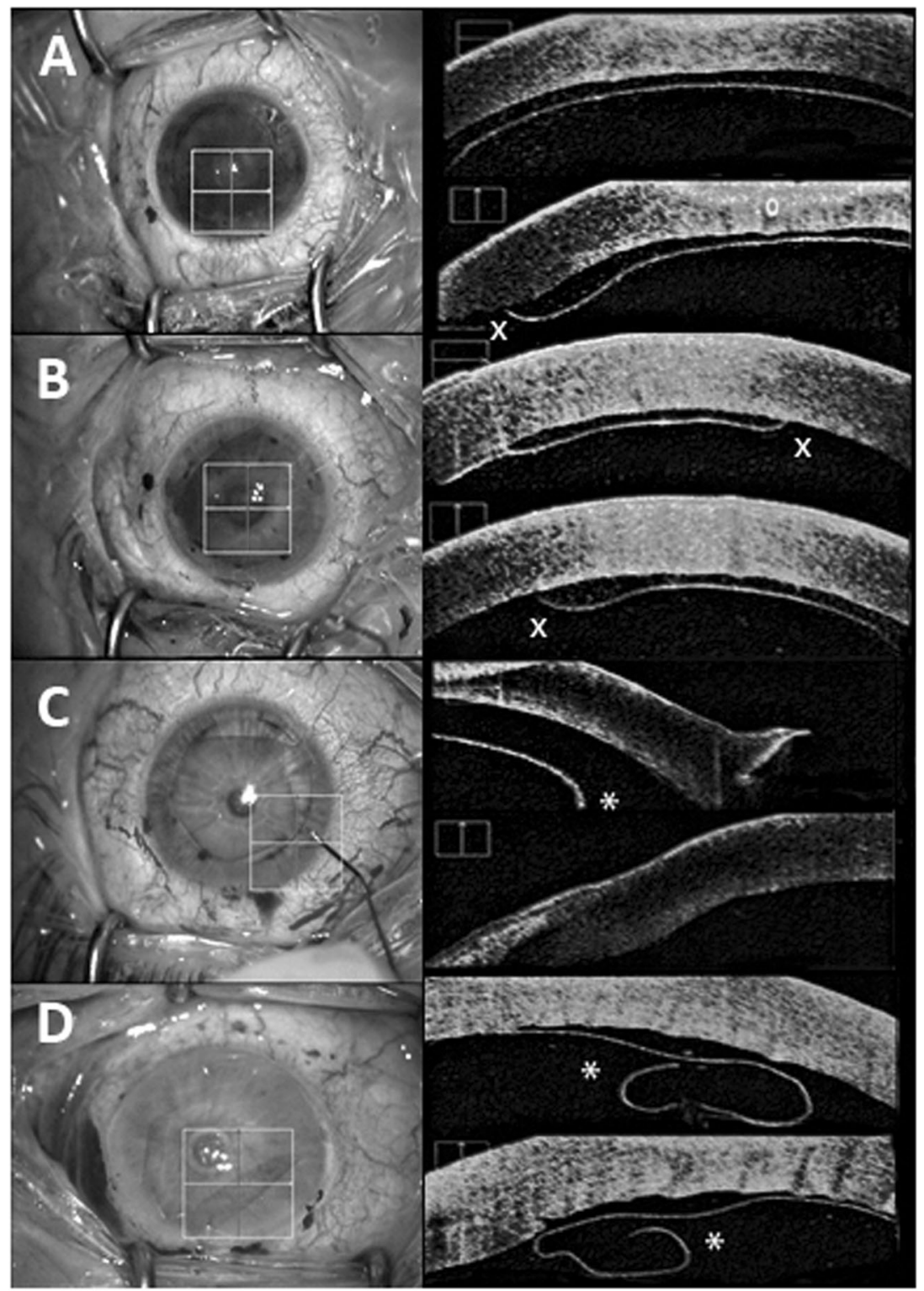

Fig. 5 Use of iOCT to observe intraocular graft geometry in two perpendicular planes (purple and turquoise crosshairs) in high detail. Shown are four examples of an en face microscope view (left column) and the unaltered OCT image (right column). The naturally curling motion of the graft in Descemet membrane endothelial keratoplasty can be used to determine the graft's orientation. In panels A and B, the " $x$ " indicates were the graft curls towards the recipient's cornea, indicating proper orientation of the graft. In panels $\mathbf{C}$ and $\mathbf{D}$, the asterisks indicate were the graft curls away from the recipient's cornea, indicating incorrect (i.e., upside-down) graft orientation.

in Supplementary Table 6. The learning curve associated with performing microsurgery-including cataract surgery-is considered both steep and demanding [102]. In this respect, the use of iOCT could improve this procedure and serve as an aid during cataract surgery training. Compared to conventional surgery, iOCT provides superior tissue visualization of the groove depth and construction of self-sealing corneal incisions, thereby enabling the supervisors to directly guide the trainee and provide feedback in real time $[103,104]$. Notwithstanding, no study to date has been performed investigating the use of IOCT during cataract surgery training.

The use of IOCT may also benefit experienced cataract surgeons for timely detection and management of surgical complications. For example, Titiyal et al. reported that Descemet membrane detachment after stromal hydration could only be observed using IOCT [104]. This is particularly relevant in the case of extensive Descemet membrane detachment, which is usually not self-resolving. Likewise, Cendelin et al. reported that stromal hydration negatively impacted incision architecture in 14 of 69 eyes and resulted in wound gaping in two cases, which subsequently required intervention [105]. Additionally, the OCT image could aid surgeons in confirming placement of the intra-ocular lens (IOL) in the capsule bag [103, 106], detecting capsular defects [107], identifying true posterior polar cataract, and confirming separation of the posterior polar plaque and capsule [103].

Importantly, studies have shown the potential of IOCT in optimizing the refractive outcome following cataract surgery. The iOCT images and the associated data provide information regarding the lens' intraocular position and can be used to optimize IOL calculations and future IOL designs. Hadded et al. reported a strong correlation between the meridian lens position and anterior chamber depth (ACD) [108]. Similarly, Hirschall et al. found that intraoperative $A C D$ measured using OCT was more representative for postoperative $A C D$ and the intraoperative $A C D$ 
was a significantly better predictor for postoperative manifest refractive outcome [109-111]. Integrating iOCT data into current IOL power calculation formulas can improve refractive outcome [111]. Hirschall et al. showed that combining preoperative and intraoperative ACD measurements refractive surprises can be reduced with 2.8 percent-point and would have resulted in a different IOL power in $7.1 \%$ of cases [111].

Furthermore, the iOCT has led to new insights regarding morphology of cataracts and effects of lens fragments. In 2016, Amir-Asgari et al. assessed the effect of swirling/pinballing lens fragments in the anterior chamber and the endothelial damage that these fragments can cause, finding that smaller particles with higher velocity tend to inflict more damage than larger, slower moving particles [112]. Titiyal et al. used the iOCT to investigate morphological characteristics and dynamics of white cataracts and posterior polar cataracts [113, 114]. Distinct characteristics of white cataract that were observed on OCT in different degrees included; the convexity of the anterior capsule, arrangement and reflectance of cortical fibers, presence of clefts, and homogenous ground glass appearance [114]. In posterior polar cataract they identified differences in delineating of the posterior capsule, reflectivity of the posterior polar opacity and underlying capsule, and adherence of the opacity to the posterior capsule [113]. Based on these features the authors propose new classification systems for these types of cataract, thereby aiding patient care and future research.

\section{GLAUCOMA SURGERY}

The goal of glaucoma surgery is to either increase the outflow of aqueous humor by drainage into the subconjunctival space or improve trabecular outflow [115]. Unfortunately, however, scleral tissue is poorly transparent to light in the visible and infrared spectrum; thus, initial experiences using $\mathrm{IOCT}$ in glaucoma surgery were rather unsuccessful in terms of providing the surgeon with improved visualization. Nevertheless, several studies have reported on the added value of IOCT in glaucoma surgery.

Most of the studies investigating the use of iOCT during glaucoma surgery consist of case reports or small case series, reporting on bleb needling [116], trabeculectomy [117], canaloplasty [118], long-tube glaucoma drainage devices [119], and angle surgery [117]. Only three studies describing iOCT use during ab-interno trabeculotomy met the inclusion criteria for this review (see Supplementary Table 7). In all three studies the authors reported that cleft and incision patterns could be observed on the OCT image after trabecular meshwork tissue removal, thereby providing an indication of the surgery's success [120-122]. Notwithstanding, all three studies noted that image acquisition was challenging and they needed a gonioprism lens for visualizing the anterior chamber angle. Only Junker et al. reported successful visualization of the trabecular meshwork without a gonioprism lens in 2 of 5 surgeries, although acquiring images took $15 \mathrm{~min}$ compared to 2-4 min for surgeries with a gonioprism lens [120]. Visualizing deeper angle structures or structures embedded in dense scleral tissue is both demanding and time-consuming-or simply not possible-using currently available OCT devices, as dense scleral tissue is impenetrable to the wavelength used in iOCT devices, thereby completely shadowing the OCT image [123]. Possible solutions to overcome the visualization challenges and improve utility of the IOCT include using a longer wavelength for better tissue penetration and adjustable scanning directions.

Furthermore, new forms of microscopic and minimally invasive surgical glaucoma procedures are coming on the market which could benefit from iOCT; small devices (e.g., stents an microshunts) often must be placed correctly in either the trabecular meshwork or the subconjunctival space/anterior chamber [124]. Placing these devices in the suprachoroidal space is another option, but is currently hampered by poor clinical success. It has not been investigated if iOCT could improve the results of suprachoroidal placements of glaucoma devices.

\section{PEDIATRIC OPHTHALMIC SURGERY}

In infants, young children, and mentally impaired patients, performing an OCT examination is often difficult-or even impossible-using a table-top OCT device. Thus, the introduction of mobile OCT devices, including handheld and microscopeintegrated devices, made it possible to exam these patients [125]. This is particularly valuable for examining new-borns and infants with a congenital eye disease, in which early structural changes were previously difficult to examine and study. Using iOCT makes it possible to examine ocular structures and the extent of the underlying pathology (see Supplementary Table 8). Furthermore, if surgical intervention is indicated, iOCT can be used to determine the degree of intervention required and assist clinical decision making (Fig. 6). For example, Hong et al. used iOCT during surgical reconstruction of the anterior segment in infants with Peter's anomaly, finding that iOCT image led to a change in the surgical approach in 7 out of 33 cases (21\%), as well as providing new information compared to both the preoperative examination and the en face ophthalmic microscope view [126]. Importantly, the use of iOCT prevented removal of the crystalline lens in 5 patients [126]. The authors concluded that disease severity in Peter's anomaly is often overestimated without the benefit of OCT examination, including overestimating the angle closure, ACD, and iridocorneal adhesion, leading the authors to conclude that OCT should be incorporated into the standard care of infants with Peter's anomaly [126]. Similarly, Bradfield et al. used iOCT to determine obstruction of the anterior chamber angle or Schlemm's canal during pediatric glaucoma surgery [127]. In 8

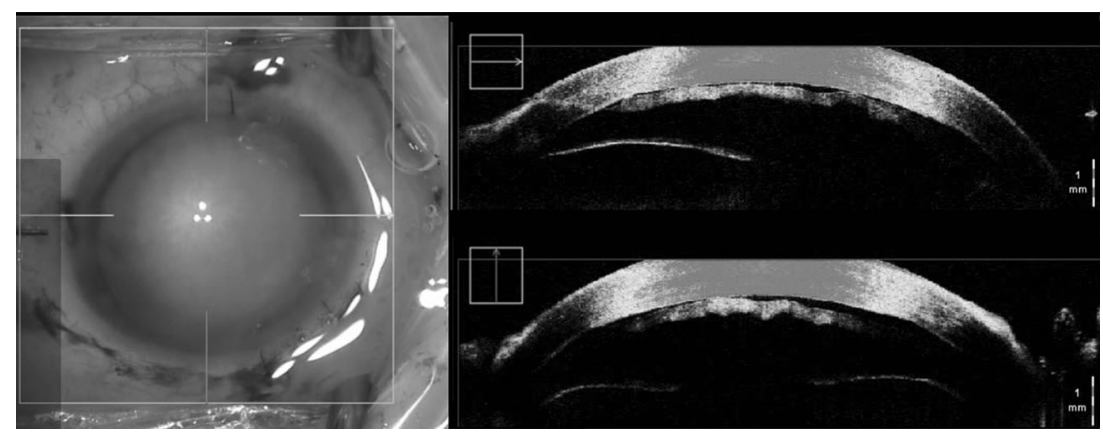

Fig. 6 A 3-month-old infant with severe posterior polymorphous dystrophy. Note that the opaque cornea precludes visualization of the anterior chamber. Shown at the right are two perpendicular planes of the corneal OCT image (the turquoise and purple crosshairs). In both OCT planes, the DSEK graft is visible as a tissue mass directly under the hyper-reflective cornea. The graft is stretched, but not yet completely attached, prior to the injection of gas. Note that iOCT was invaluable for performing endothelial keratoplasty in this infant. 
of 13 glaucomatous eyes an obstruction could be observed on the OCT image and in cases with an absent Schlemm's canal the procedure could be directly altered or reverted to a tube-shunt procedure [127].

Furthermore, Sharma et al. compared a cohort of iOCT-assisted pediatric keratoplasty's to a historical cohort [128]. The use of iOCT affected surgical decision making in $45 \%$ and $33 \%$ of anterior and posterior lamellar keratoplasty [128]. During penetrating keratoplasty significant more concomitant procedures were performed in the iOCT-assisted cohort (29/40) compared to the historical cohort (4/15) [128]. Moreover, the incidence of secondary or repeated interventions was significantly lower in the iOCT-assisted group compared to the historical cohort $(p=0.04)$ [128]. Similar, Siebelmann et al. found that IOCT proved very useful for diagnosis in pediatric patients and in 5 cases the decision to treat was directly the result of the OCT image [129].

Lastly, Pihlblad et al. investigated the potential of iOCT during pediatric strabismus surgery [130]. The extraocular muscle insertion distance was measured with different OCT devices and compared to measurements using a calliper in 19 pediatric patients. In $71 \%$ and $89 \%$ of cases the muscle insertion point was accurately visualized with, respectively, a handheld and microscope-integrated OCT device [130].

\section{Discussion and conclusion: future directions}

In this review, we summarized the current knowledge and opportunities provided by OCT during surgery. New research shows that iOCT can actively support the surgeon by providing direct, real-time feedback during surgery. This enables the surgeon - with unprecedented in-depth resolution - to review events, interactions and tissue changes intraoperatively. OCT imaging can improve the safety of surgical procedures, promote the development of novel surgical procedures, and stimulate evidence-based medicine. The use of intrasurgical biomedical imaging has drastically changed other fields of surgery and is increasingly a cornerstone of new procedures [131, 132]. In our opinion iOCT has a similar potential to advance ophthalmic surgery.

iOCT is a tool that aids in our clinical understanding of pathophysiology otherwise obscured due to poor visualization, and enabled surgeons to in vivo study their practice patterns, achieving a greater understanding of the surgical interventions and their respective tissue alterations $[20,21]$. Nevertheless the current body of research consists of low level evidence studies as the majority of studies consist of case reports/series and pilot studies. Moreover, a lot of studies lack objective measurable outcomes and are therefore poorly comparable. This is a major limitation of this review, as it is difficult to objectively quantify the putative benefits of iOCT. In addition, large studies to date focus mainly on the perceived benefits of the surgeon. Perceived benefits from a patient's perspective should arguably be addressed more in future $\mathrm{iOCT}$ research.

Admittedly, iOCT itself has inherent limitations that limit its effectiveness and utility. First, acquisition of an iOCT platform represents a significant investment for most practices. Second, IOCT is a supplementary tool and the presence of the IOCT is not essential to safely performing the surgery itself. Current use of IOCT provides surgeons with new insights and evidence shows this improves surgical management and safety; in particular the detection of complications and if possible treatment. However, it remains debatable if the use of IOCT directly leads to significantly better postoperative outcomes in routine procedures, because most studies lacked a control group or did not find significant differences in postoperative outcomes. This does not mean that altered surgical decision making using IOCT has not improved outcomes for individual patients, but it is unclear to which extend iOCT improves surgical outcomes for the general patient. Third, current methods for manually reviewing the OCT image are inefficient; thus, information that could improve surgical outcome cannot be processed easily by the surgeon [12]. Integrating of tools for automatic information processing and clinical decision aids will increase the efficacy of $\mathrm{iOCT}$, possibly rendering manual reviewing obsolete. Several groups have investigated and/or developed promising algorithms for; macular hole closure [65] or analyses of donor-recipient interface in posterior lamellar keratoplasty $[85,86,133]$. The use of augmented reality and the application of an stereoscopic OCT interface should be explored [9]. Augmented reality environments may improve the transmission of information, providing the surgeon with - at that moment the most - essential information [134]. The implementation of stereoscopic OCT opens up a new dimension and the volumetric data may be invaluable for future clinical tools [9, 133].

Two major technical limitations of iOCT should be addressed. All OCT technology is limited in the scanning speed and spatial resolution. Most iOCT platforms in use are spectral-domain OCT's with an acquisition speed of 30.000 A-scan per second, limiting the amount and quality of B-scans that can be made within a reasonable timeframe [3]. Real-time visualization of tissue manipulation requires higher a-scan rates and/or more compact scan area's [135]. The use of swept-source OCT intraoperatively could mitigate this limitation. The unprecedented high rate of Ascans per second of swept-source OCT can significantly improve image quality, acquisition speed, and therefore the effectiveness in live imaging of tissue manipulation or interventions [136]. Moreover, swept-source OCT technology uses an $1050 \mathrm{~nm}$ wavelength, which has an improved penetrating depth, aiding the use of iOCT in glaucoma surgery. The other technical limitations is most difficult to mitigate; the inability - or with considerable loss of resolution - of OCT to scan through nontransparent, opaque, or cloudy tissue, as shown by the inability to visualize thin and small structures through clouded media [103].

Frequently encountered limitations and operational hurdles in iOCT is the learning curve and ease of use. The IOCT systems can be difficult to operate and are therefore time-consuming, particularly in the case of certain types of glaucoma and vitreoretinal surgery. Targeting and focusing the IOCT image may be aided by implementation of image tracking and autofocus options. In addition, the use of metallic instruments or other nontransparent tools can obscure the surgeon's actions and cast a shadow on the tissue. However, suitable IR-transparent and iOCTcompatible instruments have been tested and will likely be available in the near future, although these instruments result in significant investments next to the iOCT-platform [12].

Lastly, advances in IOCT may also facilitated the development of robotic surgical systems, and we expect $\mathrm{IOCT}$ to reach its full potential in this field. For example, iOCT can aid navigation and provide direct feedback to the surgical robot as is already shown in the in vivo distance measurements of the Preceyes' ophthalmic surgical robot platform [137, 138].

In summary, iOCT is a promising new advancement in ophthalmic surgery with the ability to revolutionize ophthalmic surgery and improve treatment outcomes. Though adaption barriers and technical limitations need to be addressed. Ideally, future iOCT platforms should have a modular design, have image tracking and autofocus or able to handle voice-activated controls, and offer extensive review capabilities, with the ability to integrate automated image-analysis tools and compatibility with robotic surgical systems.

\section{SUMMARY}

What was known before

- Intraoperative OCT provides the surgeon with in-depth, realtime visual feedback during surgery. 
- Intraoperative OCT enables new modalities for surgical decision-making and may lead surgical safety and efficiency.

What this review adds

- This review provides a comprehensive overview of the current clinical applications of intraoperative OCT and putative benefits.

- Intraoperative OCT imaging provides opportunities for the development of novel surgical procedures/tools, and stimulates evidence-based medicine.

- Technical and operational hurdles limit the adoption and utility of intraoperative OCT.

\section{REFERENCES}

1. Fercher AF, Hitzenberger CK, Drexler W, Kamp G, Sattman SH. In vivo optical coherence tomography. Am J Ophthalmol.1993;116:113-4.

2. Schmidt-Erfurth U, Klimscha S, Waldstein SM, Bogunović H. A view of the current and future role of optical coherence tomography in the management of agerelated macular degeneration. Eye. 2017;31:26-44.

3. Fercher AF. Optical coherence tomography-development, principles, applications. Z Med Phys. 2010;20:251-76.

4. Mura M, lannetta D, Nasini F, Barca F, Peiretti E, Engelbrecht L, et al. Use of a new intra-ocular spectral domain optical coherence tomography in vitreoretinal surgery. Acta Ophthalmol. 2016;94:246-52.

5. Geerling G. Intraoperative 2-dimensional optical coherence tomography as a new tool for anterior segment surgery. Arch Ophthalmol. 2005;123:253.

6. Stehouwer M, Verbraak FD, De Vries HR, Van Leeuwen TG. Scanning beyond the limits of standard OCT with a Fourier domain optical coherence tomography integrated into a slit lamp: the SL SCAN-1. Eye. 2011;25:97-104.

7. Ehlers JP, Tao YK, Farsiu S, Maldonado R, Izatt JA, Toth CA. Integration of a spectral domain optical coherence tomography system into a surgical microscope for intraoperative imaging. Investig Ophthalmol Vis Sci. 2011;52:3153-9.

8. Binder $\mathrm{S}$, Falkner-Radler $\mathrm{Cl}$, Hauger $\mathrm{C}$, Matz H, Glittenberg C. Feasibility of intrasurgical spectral-domain optical coherence tomography. Retina. 2011;31:1332-6.

9. Shen L, Carrasco-Zevallos O, Keller B, Viehland C, Waterman G, Hahn PS, et al. Novel microscope-integrated stereoscopic heads-up display for intrasurgical optical coherence tomography. Biomed Opt Express. 2016;7:1711-26.

10. Tao YK, Srivastava SK, Ehlers JP. Microscope-integrated intraoperative OCT with electrically tunable focus and heads-up display for imaging of ophthalmic surgical maneuvers. Biomed Opt Express. 2014;5:1877-85.

11. Seider MI, Carrasco-Zevallos OM, Gunther R, Viehland C, Keller B, Shen L, et al. Real-time volumetric imaging of vitreoretinal surgery with a prototype microscope-integrated swept-source OCT device. Ophthalmol Retin. 2018;2:401-10.

12. Ehlers JP, Srivastava SK, Feiler D, Noonan Al, Rollins AM, Tao YK. Integrative advances for OCT-guided ophthalmic surgery and intraoperative OCT: microscope integration, surgical instrumentation, and heads-up display surgeon feedback. PLoS One. 2014;9:e105224.

13. Ehlers JP, Kaiser PK, Srivastava SK. Intraoperative optical coherence tomography utilizing the RESCAN 700: preliminary results from the DISCOVER study. $\mathrm{Br}$ J Ophthalmol 2014;98:1329-32.

14. Runkle A, Srivastava SK, Ehlers JP, Microscope-integrated OCT. Feasibility and utility with the EnFocus system in the DISCOVER study. Ophthalmic Surg Lasers Imaging Retin. 2017;48:216-22.

15. Moher D, Liberati A, Tetzlaff J, Altman DG. Preferred reporting items for systematic reviews and meta-analyses: the PRISMA statement. J Clin Epidemiol. 2009;62:1006-12.

16. OCEBM Levels of Evidence Working Group*. "The Oxford 2011 Levels of Evidence". Oxford Centre for Evidence-Based Medicine. http://www.cebm.net/ index.aspx?o $=5653$.

17. OCEBM Levels of Evidence Working Group*. "The Oxford Levels of Evidence 2". Oxford Centre for Evidence-Based Medicine. https://www.cebm.ox.ac.uk/ resources/levels-of-evidence/ocebm-levels-of-evidence.

18. Munn Z, Barker TH, Moola S, Tufanaru C, Stern C, McArthur A, et al. Methodological quality of case series studies: an introduction to the JBI critical appraisal tool. JBI Evid Synth. 2020;18:2127-33.

19. Guyatt G, Oxman AD, Akl EA, Kunz R, Vist G, Brozek J, et al. GRADE guidelines: 1. Introduction - GRADE evidence profiles and summary of findings tables. J Clin Epidemiol. 2011;64:383-94.
20. Ehlers JP, Dupps WJ, Kaiser PK, Goshe J, Singh RP, Petkovsek D, et al. The prospective intraoperative and perioperative ophthalmic ImagiNg with optical CoherEncE TomogRaphy (PIONEER) study: 2-year results. Am J Ophthalmol. 2014;158:999-1007.

21. Ehlers JP, Modi YS, Pecen PE, Goshe J, Dupps WJ, Rachitskaya A, et al. The DISCOVER study 3-year results: feasibility and usefulness of microscopeintegrated intraoperative OCT during ophthalmic surgery. Ophthalmology. 2018;125:1014-27.

22. Khan M, Srivastava SK, Reese JL, Shwani Z, Ehlers JP. Intraoperative OCT-assisted surgery for proliferative diabetic retinopathy in the DISCOVER study. Ophthalmol Retin. 2017;176:139-48.

23. Abraham JR, Srivastava SK, K Le T, Sharma S, Rachitskaya A, Reese JL, et al. Intraoperative OCT-assisted retinal detachment repair in the DISCOVER study: impact and outcomes. Ophthalmol Retin. 2020;4:378-83.

24. Ehlers JP, Goshe J, Dupps WJ, Kaiser PK, Singh RP, Gans R, et al. Determination of feasibility and utility of microscope-integrated optical coherence tomography during ophthalmic surgery: The DISCOVER study RESCAN results. JAMA Ophthalmol. 2015;133:1124-32.

25. Yee P, Sevgi DD, Abraham J, Srivastava SK, Le T, Uchida A, et al. iOCT-assisted macular hole surgery: outcomes and utility from the DISCOVER study. $\mathrm{Br} J$ Ophthalmol. 2021;105:403-9.

26. Knecht PB, Kaufmann C, Menke MN, Watson SL, Bosch MM. Use of intraoperative fourier-domain anterior segment optical coherence tomography during descemet stripping endothelial keratoplasty. Am J Ophthalmol. 2010;150:360-.e2.

27. Han S, Sarunic MV, Wu J, Humayun M, Yang C. Handheld forward-imaging needle endoscope for ophthalmic optical coherence tomography inspection. J Biomed Opt. 2008;13:1-3.

28. Joos KM, Shen J-H. Miniature real-time intraoperative forward-imaging optical coherence tomography probe. Biomed Opt Express. 2013;4:1342.

29. Leisser C, Hirnschall N, Hackl C, Döller B, Varsits R, Findl O. Diagnostic precision of a microscope-integrated intraoperative OCT device in patients with epiretinal membranes. Eur J Ophthalmol. 2018;28:329-32.

30. Ehlers JP, Griffith JF, Srivastava SK. Intraoperative OCT during Vitreoretinal Surgery for Dense Vitreous Hemorrhage in the PIONEER Study. Retina . 2015;35:2537-42.

31. Tao J, Wu H, Chen Y, Mao J, Cheng D, Lin J, et al. Use of iOCT in vitreoretinal surgery for dense vitreous hemorrhage in a chinese population. Curr Eye Res. 2019;44:219-24.

32. Jusufbegovic D, Ozkok A, Schaal S. Intraoperative optical coherence tomography validates the immediate efficacy of external diathermy in sealing 25gauge sclerotomy wounds. Retina. 2017;37:402-4.

33. Bruyère $E$, Philippakis $E$, Dupas $B$, Nguyen-Kim $P$, Tadayoni $R$, Couturier $A$. Benefit of intraoperative optical coherence tomography for vitreomacular surgery in highly myopic eyes. Retina. 2018;38:2035-44.

34. Ehlers JP, Tam T, Kaiser PK, Martin DF, Smith GM, Srivastava SK. Utility of intraoperative optical coherence tomography during vitrectomy surgery for vitreomacular traction syndrome. Retina. 2014;34:1341-6.

35. Rachitskaya AV, Yuan A, Marino MJ, Reese J, Ehlers JP, Intraoperative OCT. Imaging of the Argus II retinal prosthesis system. Ophthalmic Surg Lasers Imaging Retin. 2015;46:964-6.

36. Kashani AH, Uang J, Mert M, Rahhal F, Chan C, Avery RL, et al. Surgical method for implantation of a biosynthetic retinal pigment epithelium monolayer for geographic atrophy: experience from a phase 1/2a study. Ophthalmol Retin. 2020;4:264-73.

37. Kumar JB, Ehlers JP, Sharma S, Srivastava SK. Intraoperative OCT for uveitisrelated vitreoretinal surgery in the DISCOVER study. Ophthalmol Retin. 2018;2:1041-9.

38. Asahina $Y$, Tachi N, Asahina $Y$, Yoshimura K, Ueta $Y$, Hashimoto $Y$. Six-month postoperative outcomes of intraoperative OCT-guided surgical cystotomy for refractory cystoid macular edema in diabetic eyes. Clin Ophthalmol. 2017;11:2099-105.

39. Vasconcelos HM, Lujan BJ, Pennesi ME, Yang P, Lauer AK. Intraoperative optical coherence tomographic findings in patients undergoing subretinal gene therapy surgery. Int J Retin Vitr. 2020;6:1-10.

40. Dayani PN, Maldonado R, Farsiu S, Toth CA. Intraoperative use of handheld spectral domain optical coherence tomography imaging in macular surgery. Retina. 2009;29:1457-68.

41. Falkner-Radler Cl, Glittenberg C, Gabriel M, Binder S. Integrated spectral domain optical coherence tomography - assisted membrane peeling. Retina. 2015;35:2100-6.

42. Kumar A, Ravani R, Mehta A, Simakurthy S, Dhull C. Outcomes of microscopeintegrated intraoperative optical coherence tomography-guided center-sparing internal limiting membrane peeling for myopic traction maculopathy: a novel technique. Int Ophthalmol. 2018;38:1689-96. 
43. Leisser C, Hirnschall N, Palkovits S, Doeller B, Kefer K, Findl O. Intraoperative optical coherence tomography-guided membrane peeling for surgery of macular pucker: advantages and limitations. Ophthalmologica. 2019;241:234-40.

44. Leisser C, Hackl C, Hirnschall N, Luft N, Döller B, Draschl P, et al. Visualizing macular structures during membrane peeling surgery with an intraoperative spectral-domain optical coherence tomography device. Ophthalmic Surg Lasers Imaging Retina. 2016;47:328-32.

45. Ehlers JP, McNutt S, Dar S, Tao YK, Srivastava SK. Visualisation of contrastenhanced intraoperative optical coherence tomography with indocyanine green. Br J Ophthalmol. 2014;98:1588-91.

46. Ehlers JP, Xu D, Kaiser PK, Singh RP, Srivastava SK. Intrasurgical dynamics of macular hole surgery: an assessment of surgery-induced ultrastructural alterations with intraoperative optical coherence tomography. Retina. 2014;34:213-21.

47. Ehlers JP, Han J, Petkovsek D, Kaiser PK, Singh RP, Srivastava SK. Membrane peeling-induced retinal alterations on intraoperative OCT in vitreomacular interface disorders from the PIONEER study. Invest Ophthalmol Vis Sci. 2015;56:7324-30.

48. Uchida A, Srivastava SK, Ehlers JP. Analysis of retinal architectural changes using intraoperative OCT following surgical manipulations with membrane flex loop in the DISCOVER study. Invest Ophthalmol Vis Sci. 2017;58:3440-4.

49. Itoh Y, Inoue M, Kato Y, Koto T, Hirakata A. Alterations of foveal architecture during vitrectomy for myopic retinoschisis identified by intraoperative optical coherence tomography. Ophthalmologica. 2019;242:87-97.

50. Ray R, Barañano DE, Fortun JA, Schwent BJ, Cribbs BE, Bergstrom CS, et al. Intraoperative microscope-mounted spectral domain optical coherence tomography for evaluation of retinal anatomy during macular surgery. Ophthalmology. 2011;118:2212-7.

51. Ehlers JP, Itoh $Y, X u L T$, Kaiser PK, Singh RP, Srivastava SK. Factors associated with persistent subfoveal fluid and complete macular hole closure in the PIONEER study. Investig Ophthalmol Vis Sci. 2014;56:1141-6.

52. Ehlers JP, Khan M, Petkovsek D, Stiegel L, Kaiser PK, Singh RP, et al. Outcomes of intraoperative OCT-assisted epiretinal membrane surgery from the PIONEER study. Ophthalmol Retin. 2018;2:263-7.

53. Leisser C, Hackl C, Hirnschall N, Findl O. Effect of subfoveal and extrafoveal hyporeflective zones due to iatrogenic traction during membrane peeling for epiretinal membranes on postoperative outcomes. Ophthalmologica. 2020;243:297-302.

54. Leisser C, Hirnschall N, Hackl C, Döller B, Varsits R, Ullrich M, et al. Risk factors for postoperative intraretinal cystoid changes after peeling of idiopathic epiretinal membranes among patients randomized for balanced salt solution and airtamponade. Acta Ophthalmol. 2018;96:e439-e444.

55. Leisser C, Hirnschall N, Döller B, Varsits R, Ullrich M, Kefer K, et al. Effect of air tamponade on postoperative visual acuity and intraretinal cystoid changes after peeling of idiopathic epiretinal membranes in pseudophakic patients. Ophthalmologica. 2020;243:37-42.

56. Leisser C, Palkovits S, Hienert J, Ullrich M, Zwickl H, Georgiev S, et al. Effect of iatrogenic traction during macular peeling surgery on postoperative microperimetry. Ophthalmic Res. 2021;64:273-9.

57. Runkle AP, Srivastava SK, Yuan A, Kaiser PK, Singh RP, Reese JL, et al. Factors Associated with Development of Dissociated Optic Nerve Fiber Layer (DONFL) appearance in the PIONEER intraoperative OCT study. Retina. 2018;38:103-9.

58. Hayashi A, Yagou T, Nakamura T, Fujita K, Oka M, Fuchizawa C. Intraoperative changes in idiopathic macular holes by spectral-domain optical coherence tomography. Case Rep Ophthalmol. 2011;2:149-54.

59. Lytvynchuk LM, Falkner-Radler Cl, Krepler K, Glittenberg CG, Ahmed D, Petrovski $\mathrm{G}$, et al. Dynamic intraoperative optical coherence tomography for inverted internal limiting membrane flap technique in large macular hole surgery. Graefes Arch Clin Exp Ophthalmol. 2019;257:1649-59.

60. Lorusso M, Micelli Ferrari L, Cicinelli MV, Nikolopoulou E, Zito R, Bandello F, et al. Feasibility and safety of intraoperative optical coherence tomography-guided short-term posturing prescription after macular hole surgery. Ophthalmic Res. 2020;63:18-24.

61. Kumar V, Yadav B. A novel intraoperative optical coherence tomography feature predicting macular hole closure. Retina. 2018;38:2045-50.

62. Inoue $M$, Itoh $Y$, Koto $T$, Kurimori HY, Hirakata A, Intraoperative OCT. Findings may predict postoperative visual outcome in eyes with idiopathic macular hole. Ophthalmol Retin. 2019;3:962-70.

63. Tao J, Chen H, Zhu L, Pan D, Fang J, Chen Y, et al. Macular hole edge morphology predicts restoration of postoperative retinal microstructure and functional outcome. BMC Ophthalmol. 2020;20:280.

64. Riazi-Esfahani M, Khademi MR, Mazloumi M, Khodabandeh A, Riazi-Esfahani H. Macular surgery using intraoperative spectral domain optical coherence tomography. J Ophthalmic Vis Res. 2015;10:309-15.
65. Ehlers JP, Uchida A, Srivastava SK, Hu M. Predictive model for macular hole closure speed: insights from intraoperative optical coherence tomography. Transl Vis Sci Technol. 2019;8:18.

66. Nam DH, Desouza PJ, Hahn P, Tai V, Sevilla MB, Tran-Viet D, et al. Intraoperative spectral domain optical coherence tomography imaging after internal limiting membrane peeling in idiopathic epiretinal membrane with connecting strands. Retina. 2015;35:1622-30.

67. Gabr H, Chen X, Zevallos-Carrasco OM, Viehland C, Dandrige A, Sarin N, et al. Visualization from intraoperative swept-source microscope-integrated optical coherence tomography in vitrectomy for complications of proliferative diabetic retinopathy. Retina. 2018;38:S110-S120.

68. Toygar O, Riemann CD. Intraoperative optical coherence tomography in macula involving rhegmatogenous retinal detachment repair with pars plana vitrectomy and perfluoron. Eye. 2016;30:23-30.

69. Leisser C, Varsits R, Findl O. Does perfluoro-n-octane use in 23G vitrectomy for retinal detachment surgery affect the integrity of the ellipsoid zone? Eur J Ophthalmol. 2016;26:639-42.

70. Abraham JR, Srivastava SK, Reese JL, Ehlers JP, Intraoperative OCT. Features and postoperative ellipsoid mapping in primary macula-involving retinal detachments from the PIONEER study. Ophthalmol Retin. 2019:3:252-7.

71. Ehlers JP, Ohr MP, Kaiser PK, Srivastava SK. Novel microarchitectural dynamics in rhegmatogenous retinal detachments identified with intraoperative optical coherence tomography. Retina. 2013;33:1428-34.

72. Scorcia V, Busin M, Lucisano A, Beltz J, Carta A, Scorcia G. Anterior segment optical coherence tomography-guided big-bubble technique. Ophthalmology. 2013;120:471-6.

73. Au J, Goshe JG, Dupps WJ Jr, Srivastava SK, Ehlers JP. Intraoperative optical coherence tomography for enhanced depth visuaization in DALK from PIONEER study. Cornea. 2016;34:1039-43.

74. Steven P, Le Blanc C, Lankenau E, Krug M, Oelckers S, Heindl LM, et al. Optimising deep anterior lamellar keratoplasty (DALK) using intraoperative online optical coherence tomography (iOCT). Br J Ophthalmol. 2014;98:900-4.

75. De Benito-Llopis L, Mehta JS, Angunawela Rl, Ang M, Tan DTH. Intraoperative anterior segment optical coherence tomography: a novel assessment tool during deep anterior lamellar keratoplasty. Am J Ophthalmol. 2014;157:334-e3.

76. Guindolet D, Nguyen DT, Bergin C, Doan S, Cochereau I, Gabison EE. Doubledocking technique for femtosecond laser-assisted deep anterior lamellar keratoplasty. Cornea. 2018;37:123-6.

77. Zakaria N, Ní Dhubhghaill S, Taal M, Berneman Z, Koppen C, Tassignon M-J. Optical coherence tomography in cultivated limbal epithelial stem cell transplantation surgery. Asia-Pac J Ophthalmol. 2015;4:339-45.

78. Melles GRJ. Posterior lamellar keratoplasty. Cornea. 2006;25:879-81.

79. Muijzer MB, Soeters N, Godefrooij DA, van Luijk CM, Wisse RPL. Intraoperative optical coherence tomography-assisted descemet membrane endothelial keratoplasty: toward more efficient, safer surgery. Cornea. 2020;39:674-9.

80. Juthani VV, Goshe JM, Srivastava SK, Ehlers JP. The association between transient interface fluid on intraoperative OCT and textural interface opacity following DSAEK surgery in the PIONEER study. Cornea. 2014;33:887-92.

81. Miyakoshi A, Ozaki H, Otsuka M, Hayashi A. Efficacy of intraoperative anterior segment optical coherence tomography during Descemet's stripping automated endothelial keratoplasty. ISRN Ophthalmol. 2014;2014:562062.

82. Sng C, Gimeno FL, Mehta JS, Htoon HM, Tan DT. Intraoperative use of spectraldomain optical coherence tomography during Descemet's stripping automated endothelial keratoplasty. Clin Ophthalmol. 2012;6:479-86.

83. Steverink JG, Wisse RPL. Intraoperative optical coherence tomography in descemet stripping automated endothelial keratoplasty: pilot experiences. Int Ophthalmol. 2017;37:939-44.

84. Cost B, Goshe JM, Srivastava S, Ehlers JP. Intraoperative optical coherence tomography-assisted descemet membrane endothelial keratoplasty in the DISCOVER study. Am J Ophthalmol. 2015;160:430-7.

85. Xu D, Dupps WJJ, Srivastava SK, Ehlers JP. Automated volumetric analysis of interface fluid in descemet stripping automated endothelial keratoplasty using intraoperative optical coherence tomography. Invest Ophthalmol Vis Sci. 2014;55:5610-5.

86. Hallahan KM, Cost B, Goshe JM, Dupps WJ, Srivastava SK, Ehlers JP. Intraoperative interface fluid dynamics and clinical outcomes for intraoperative optical coherence tomography-assisted descemet stripping automated endothelial keratoplasty from the PIONEER study. Am J Ophthalmol. 2017;173:16-22.

87. Titiyal JS, Kaur M, Falera R, Jose CP, Sharma N. Evaluation of time to donor lenticule apposition using intraoperative optical coherence tomography in descemet stripping automated endothelial keratoplasty. Cornea. 2016;35:477-81.

88. Patel AS, Goshe JM, Srivastava SK, Ehlers JP. Intraoperative optical coherence tomography-assisted descemet membrane endothelial keratoplasty in the DISCOVER study: first 100 cases. Am J Ophthalmol. 2020;210:167-73. 
89. Sharma N, Sahay P, Maharana PK, Kumar P, Ahsan S, Titiyal JS. Microscope integrated intraoperative optical coherence tomography-guided DMEK in corneas with poor visualization. Clin Ophthalmol. 2020;14:643-51.

90. Steven P, Le Blanc C, Velten K, Lankenau E, Krug M, Oelckers S, et al. Optimizing Descemet membrane endothelial keratoplasty using intraoperative optical coherence tomography. JAMA Ophthalmol. 2013;131:1135-42.

91. Saad A, Guilbert E, Grise-Dulac A, Sabatier P, Gatinel D. Intraoperative OCTassisted DMEK: 14 consecutive cases. Cornea. 2015;34:802-7.

92. Godefrooij DA, Gans R, Imhof SM, Wisse RPL. Nationwide reduction in the number of corneal transplantations for keratoconus following the implementation of cross-linking. Acta Ophthalmol. 2016;94:675-8.

93. Pahuja N, Shetty R, Jayadev C, Nuijts R, Hedge B, Arora V. Intraoperative optical coherence tomography using the RESCAN 700: Preliminary results in collagen crosslinking. Biomed Res Int. 2015;2015:572698.

94. Chow VWS, Biswas S, Yu M, Wong VWY, Jhanji V. Intraoperative pachymetry using spectral-domain optical coherence tomography during accelerated corneal collagen crosslinking. Biomed Res Int. 2013;2013:848363.

95. Ghaffari R, Mortazavi M, Anvari P, Salamat Rad A, Alipour F, Hafezi F, et al. Intraoperative optical coherence tomography to evaluate the effect of the eyelid speculum on corneal pachymetry during accelerated corneal crosslinking (9 mW/cm(2)). Eye. 2018;32:579-85.

96. Rechichi M, Mazzotta C, Daya S, Mencucci R, Lanza M, Meduri A, et al. Pachymetry in patients undergoing dextran-free riboflavin UVA accelerated corneal collagen crosslinking. Curr Eye Res. 2016;41:1310-5.

97. Ye C, Yu M, Jhanji V. Stromal bed thickness measurement during laser in situ keratomileusis using intraoperative optical coherence tomography. Cornea. 2015;34:387-91.

98. Siebelmann S, Horstmann J, Scholz P, Bachmann B, Matthaei M, Hermann M, et al. Intraoperative changes in corneal structure during excimer laser phototherapeutic keratectomy (PTK) assessed by intraoperative optical coherence tomography. Graefe's Arch Clin Exp Ophthalmol. 2018;256:575-81.

99. Titiyal JS, Kaur M, Sahu S, Sharma N, Sinha R. Real-time assessment of intraoperative vaulting in implantable collamer lens and correlation with postoperative vaulting. Eur J Ophthalmol. 2017;27:21-25.

100. Torbey J, Mehanna C-J, Abdul Fattah M, Awwad ST. Comparison of intraoperative vs postoperative optical coherence tomography measurement of implantable collamer lens vaulting. J Cataract Refract Surg. 2020;46:737-41.

101. Bell CM, Hatch WV, Cernat G, Urbach DR. Surgeon volumes and selected patient outcomes in cataract surgery. A population-based analysis. Ophthalmology. 2007;114:405-10.

102. Ramachandran S, Ghanem AM, Myers SR. Assesment of microsurgery competency - where are we now? Microsurgery. 2013;33:406-15.

103. Das S, Kummelil MK, Kharbanda V, Arora V, Nagappa S, Shetty R, et al. Microscope integrated intraoperative spectral domain optical coherence tomography for cataract surgery: uses and applications. Curr Eye Res. 2016;41:643-52.

104. Titiyal JS, Kaur M, Ramesh P, Shah P, Falera R, Bageshwar LMS, et al. Impact of clear corneal incision morphology on incision-site descemet membrane detachment in conventional and femtosecond laser-assisted phacoemulsification. Curr Eye Res. 2018;43:293-9.

105. Cendelin J, Rusnak S, Hecova L. Intraoperative optical coherence tomography analysis of clear corneal incision: effect of the lateral stromal hydration. J Ophthalmol. 2020;2020:8490181.

106. Lytvynchuk LM, Glittenberg CG, Falkner-Radler Cl, Neumaier-Ammerer $B$, Smretschnig E, Hagen $S$, et al. Evaluation of intraocular lens position during phacoemulsification using intraoperative spectral-domain optical coherence tomography. J Cataract Refract Surg. 2016;42:694-702.

107. Sachdev MS, Malik R, Gupta H, Sachdev R, Sachdev GS. Femtosecond laserintegrated anterior segment optical coherence tomography to detect preexisting posterior capsular dehiscence and increase safety in posterior polar cataracts. J Cataract Refract Surg. 2020;46:235-40.

108. Haddad JS, Rocha KM, Yeh K, Waring GO 4th. Lens anatomy parameters with intraoperative spectral-domain optical coherence tomography in cataractous eyes. Clin Ophthalmol. 2019;13:253-60.

109. Hirnschall N, Norrby S, Weber M, Maedel S, Amir-Asgari S, Findl O. Using continuous intraoperative optical coherence tomography measurements of the aphakic eye for intraocular lens power calculation. $\mathrm{Br} J$ Ophthalmol. 2015;99:7-10.

110. Hirnschall N, Amir-Asgari S, Maedel S, Findl O. Predicting the postoperative intraocular lens position using continuous intraoperative optical coherence tomography measurements. Invest Ophthalmol Vis Sci. 2013;54:5196-203.

111. Hirnschall N, Farrokhi S, Amir-Asgari S, Hienert J, Findl O. Intraoperative optical coherence tomography measurements of aphakic eyes to predict postoperative position of 2 intraocular lens designs. J Cataract Refract Surg. 2018;44:1310-6.

112. Amir-Asgari S, Hirnschall N, Findl O. Using continuous intraoperative optical coherence tomography to classify swirling lens fragments during cataract surgery and to predict their impact on corneal endothelial cell damage. J Cataract Refract Surg. 2016;42:1029-36.

113. Titiyal JS, Kaur M, Shaikh F, Rani D, Bageshwar LMS. Elucidating intraoperative dynamics and safety in posterior polar cataract with intraoperative OCT-guided phacoemulsification. J Cataract Refract Surg. 2020;46:1266-72.

114. Titiyal JS, Kaur M, Shaikh F, Goel S, Bageshwar LMS. Real-time intraoperative dynamics of white cataract-intraoperative optical coherence tomographyguided classification and management. J Cataract Refract Surg. 2020;46:598-605

115. Jonas JB, Aung T, Bourne RR, Bron AM, Ritch R, Panda-Jonas S. Glaucoma. Lancet. 2017;390:2183-93.

116. Dada T, Angmo D, Midha N, Sidhu T. Intraoperative optical coherence tomography guided bleb needling. J Ophthalmic Vis Res. 2016;11:452-4.

117. Kumar RS, Jariwala MU, V SA, Venugopal JP, Puttaiah NK, Balu R, et al. A pilot study on feasibility and effectiveness of intraoperative spectral-domain optical coherence tomography in glaucoma procedures. Transl Vis Sci Technol. 2015;4:2.

118. Siebelmann S, Cursiefen C, Lappas A, Dietlein T. Intraoperative optical coherence tomography enables noncontact imaging during canaloplasty. J Glaucoma. 2016;25:236-8.

119. Swaminathan SS, Chang TC. Use of intraoperative optical coherence tomography for tube positioning in glaucoma surgery. JAMA Ophthalmol. 2017;135:1438-9.

120. Junker B, Jordan JF, Framme C, Pielen A. Intraoperative optical coherence tomography and ab interno trabecular meshwork surgery with the Trabectome. Clin Ophthalmol. 2017;11:1755-60.

121. Tanito M. Optical coherence tomography observation of Gonio structures during Microhook Ab Interno Trabeculotomy. J Ophthalmol. 2017;2017:6310835

122. Ishida A, Sugihara K, Shirakami T, Tsutsui A, Manabe K, Tanito M. Observation of Gonio structures during Microhook Ab Interno Trabeculotomy using a novel digital microscope with integrated intraoperative optical coherence tomography. J Ophthalmol. 2020;2020:9024241.

123. Heindl LM, Siebelmann S, Dietlein T, Hüttmann G, Lankenau E, Cursiefen C, et al. Future prospects: assessment of intraoperative optical coherence tomography in ab interno glaucoma surgery. Curr Eye Res. 2015;40:1288-91.

124. King AJ, Shah A, Nikita E, Hu K, Mulvaney CA, Stead R, Azuara-Blanco A. Subconjunctival draining minimally-invasive glaucoma devices for medically uncontrolled glaucoma. Cochrane Database Syst Rev. 2018;12:CD012742.

125. Maldonado RS, Izatt JA, Sarin N, Wallace DK, Freedman S, Cotten CM, et al. Optimizing hand-held spectral domain optical coherence tomography imaging for neonates, infants, and children. Investig Ophthalmol Vis Sci. 2010;51:2678-85.

126. Hong J, Yang Y, Cursiefen C, Mashaghi A, Wu D, Liu Z, et al. Optimising keratoplasty for Peters' anomaly in infants using spectral-domain optical coherence tomography. Br J Ophthalmol. 2017;101:820-7.

127. Bradfield Y, Barbosa T, Blodi B, Tompson SW, McLellan GJ, Struck M, et al. Comparative intraoperative anterior segment OCT findings in pediatric patients with and without glaucoma. Ophthalmol Glaucoma. 2019;2:232-9.

128. Sharma N, Priyadarshini K, Agarwal R, Bafna RK, Nagpal R, Sinha R, et al. Role of microscope-intraoperative optical coherence tomography in paediatric keratoplasty: a comparative study. Am J Ophthalmol. 2021;221:190-8.

129. Siebelmann S, Hermann M, Dietlein T, Bachmann B, Steven P, Cursiefen C. Intraoperative optical coherence tomography in children with anterior segment anomalies. Ophthalmology. 2015;122:2582-4.

130. Pihlblad MS, Troia A, Tibrewal S, Shah PR. Pre-, intra-, and post-operative evaluation of extraocular muscle insertions using optical coherence tomography: a comparison of four devices J Clin Med. 2019;8:1732.

131. Mascagni $P$, Longo $F$, Barberio $M$, Seeliger $B$, Agnus V, Saccomandi $P$, et al. New intraoperative imaging technologies: innovating the surgeon's eye toward surgical precision. J Surg Oncol. 2018;118:265-82.

132. Valdés PA, Roberts DW, Lu F-K, Golby A. Optical technologies for intraoperative neurosurgical guidance. Neurosurg Focus. 2016;40:E8.

133. Carrasco-Zevallos OM, Keller B, Viehland C, Shen L, Waterman G, Todorich B, et al. Live volumetric (4D) visualization and guidance of in vivo human ophthalmic surgery with intraoperative optical coherence tomography. Sci Rep. 2016;6:1-16.

134. Draelos M, Keller B, Viehland C, Carrasco-Zevallos OM, Kuo A, Izatt J. Real-time visualization and interaction with static and live optical coherence tomography volumes in immersive virtual reality. Biomed Opt Express. 2018;9:2825-43.

135. Ehlers JP, Tao Y. Visualization of real-time intraoperative maneuvers with a microscope-mounted spectrual domain optical coherence tomography system. Retina. 2013;33:232-6.

136. Kishi S. Impact of swept source optical coherence tomography on ophthalmology. Taiwan J Ophthalmol. 2016;6:58-68. 
137. Edwards TL, Xue K, Meenink HCM, Beelen MJ, Naus GJL, Simunovic MP, et al. First-in-human study of the safety and viability of intraocular robotic surgery. Nat Biomed Eng. 2018;2:649-56.

138. Roizenblatt M, Edwards TL, Gehlbach PL. Robot-assisted vitreoretinal surgery: current perspectives. Robot Surg. 2018;5:1-11.

\section{ACKNOWLEDGEMENTS}

The authors are grateful to Nikita Witzenburg, for her assistance in the literature search, assessing the level and quality of evidence, and the critical appraisal of the studies, and to Curtis Barrett PhD for his English editing services. This research is financially supported by unrestricted grants provided by the F.P. Fischer Foundation and Zeiss $\mathrm{GmbH}$.

\section{AUTHOR CONTRIBUTIONS}

MBM was responsible for design of the review protocol, writing the report conducting the search, screening potentially eligible studies, extracting and analyzing data, interpreting results, updating reference lists and creating'Summary of findings' tables. RPLW was responsible for design of the review protocol, and contributed to writing the report, arbitrating potentially eligible studies, and critical revision of the report. PAWJS, HJMB, JHdB, SMI, provided feedback on the report.

\section{COMPETING INTERESTS}

The authors have no financial or proprietary interest in the information presented herein. MBM and RPLW are supported by an unrestricted grant from the Dr. F.P. Fischer Foundation, facilitated by the Foundation Friends from the UMC Utrecht, and supported by an unrestricted grant from Zeiss $\mathrm{GmHb}$.

\section{ADDITIONAL INFORMATION}

Supplementary information The online version contains supplementary material available at https://doi.org/10.1038/s41433-021-01686-9.

Correspondence and requests for materials should be addressed to M.B.M.

Reprints and permission information is available at http://www.nature.com/ reprints

Publisher's note Springer Nature remains neutral with regard to jurisdictional claims in published maps and institutional affiliations. 